[Jpn. J. Rural Econ. Vol. 7, pp.100-113, 2005]

\title{
Effects of Image Formation of Rural Lifescape on Consciousness and Willingness to Protect Rural Farming Villages
}

\author{
Shinobu Kitani*, Tadashi Hasebe*, Noriaki Nomura* and \\ Richard Moore $^{\dagger}$
}

\begin{abstract}
The paper aims to evaluate rural farming villages through an ethical view point. The method of evaluation is to grasp respondents' changes of attitudes in a CVM survey, where we show them many photos relating to a Japanese rural farming village. These photos are classified by trilateral images of the village and we ask respondents to make pair-wise comparisons in each set of photos. As a result, we can verify that respondents who have much past experience in a rural farming village would have an image of life and their attitudes for CVM judgment are more prone to be vulnerable to visual information (photos). This means that images of rural lifescape might not be reflected in the values calculated through CVM.
\end{abstract}

Key words : AHP, change of attitude, contingent valuation, CVM, image formation, lifescape, rural farming village.

\section{Introduction}

Recently, many learned experts say that in addition to agricultural products the multifunctional value of agriculture includes the reduction of natural disasters, landscape of farming villages, and cultural or historical materials around the villages. In fact, there have been many papers which evaluate these values by means of various econometric methods, e.g. hedonic, travel cost, contingent value (CVM), and conjoint method. These methods are all based on the market models. These methods assume that the total value of agriculture can be objectively measured by hypothetical market prices which might be determined by behaviors or actions of rational citizens. Is this a reasonable assumption?

Much of the value of agriculture should be evaluated as symbolic rather than instrumental because it is related to the labor and lives

\footnotetext{
* Tohoku University

†Ohio Agricultural Research \& Development

Center, U.S. A.
}

of citizens living in villages. ${ }^{1)}$ Referring to Sagoff [17], it is fair to say that the worth of the things we love is better measured by our unwillingness to pay for them (p.68). But there is no research that focuses on measuring the symbolic value directly. This would arise from the fact that we all have considered that the symbolic value can not or should not be measured, even if the value has an important role in the evaluation of agricultural environments. Although we admit there is difficulty in measuring the value, it would be mistaken to evaluate farming villages without considering it.

Some established researchers who have presented a plausible view of rural farming villages (RFV) take note of the importance of intrinsic values ${ }^{2)}$ but have not included them in their analyses due to the difficulty in representing their values numerically. So their policy proposals for protecting RFV lack effectiveness when implemented. Though it is wrong to measure the values by econometric methods and add them to the other economic values such as productivity, it would be important to measure or grasp the meaning of 
symbolic values "objectively" by some reasonable methods.

In fact, it is very difficult for persons who do not live or have not lived in RFV to judge or meaningfully represent their preferences on agricultural policies. The possible way that we can do this is to find a number of factors underlying expressions and attitudes for or against a policy regarding preservation of rural villages. Of course, researchers sometimes construct surveys using econometric methods to ask people's views about regional planning and investigate the relations between these views and other attributes. ${ }^{3)}$ But this approach is based on economic models which aim to evaluate policies using an econometric framework (that is, econometrics is based on an aggregation or an average of subjects' views in policy evaluation). If we try to evaluate a policy in addition to its aggregated values using econometric methods, we think it is necessary to pay attention to each individual's view and its variation in space and time. Moreover, it may be possible to analyze changes of subject's views after presenting some real photos or movies in relation to landscape, life, or culture of a certain farming village. Citizens have various images of rural scenery, and those formations were created in their environment during the time they grew up. If we present many photos of farming villages repeatedly to them, they might go through a process of image transformation that enables prior experiences to affect their attitudes regarding policies about farming village preservation.

The paper aims to clarify the relationship between attitudes affecting willingness to pay for conserving the landscape of rural farming villages and the image of rural lifescape. By lifescape we mean the interrelationship between the daily life of people, their culture and history, and their environment. ${ }^{4)}$ The relationship might give us a new evaluation framework for preserving RFV, which would be related to agricultural ethics. The research was conducted using a personal computer (PC) automatic questionnaire system, where subjects were young persons who were students about 20 years of age. We can assume that they all had little relationship with farming villages at the time they took the questionnaire.

\section{Image Formation about Rural Lifescape and Atitudes for Preserving Faming Villages}

\section{1) Model for image formation about rural lifescape}

The attitude for the preservation of RFV must be influenced by the mental image regarding rural lifescape, and the differences in past experiences regarding RFV in childhood brought about the different images when they took the PC questionnaire. Moreover, the experiences in RFV were probably acquired in physical and social environments, i. e. whether or not they lived near a farming village or whether their parents were engaged in agriculture. We show the causal relationship stated above in Fig. 1.

We assume that the image of rural lifescape consists of the following three components :

(1) The image of nature : greenish woods, scarlet-tinged (autumn) leaves, small streams, landscape with a hill in the background

(2) The image of life : cultivating farmland, children playing in a field, enjoying a relaxing break

(3) The image of culture and history: woods in former residences, historical buildings, temples, festivals, long-established traditions

Most environmental economists have assumed that the image of nature and history could partially be reflected by economic values as if we consume lifescape in the same way we do private goods. In fact, there are so many papers where authors try to clarify the economic value of natural landscapes or historical and cultural architecture on the assumption that we can buy them under some contingent markets. ${ }^{5)}$ In this paper, the image of life is focused on more than the other two components of the image, because we think that the image of life is more closely related to an individual's past proximity and contact with farming villages. According to Fig. 1, past proximity and contact are defined by natural and social environments and experiences when a subject was a child. Here, we formulate the first hypothesis.

H1: The image of life will be enhanced by natural and social environments of rural farming villages via past experiences in the farming villages. 
(Natural environments)

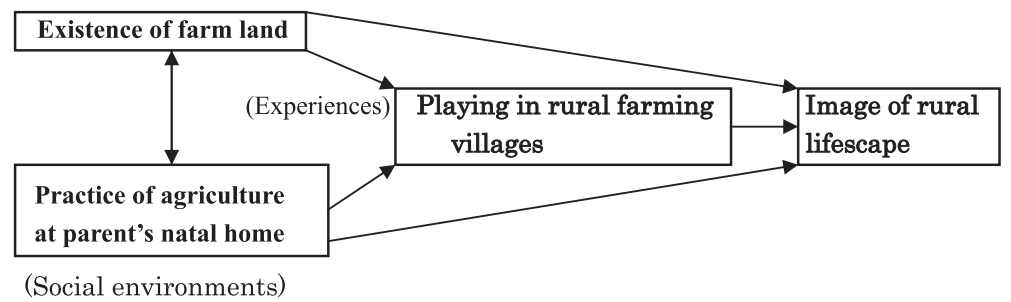

Figure 1. The model for image formation of rural lifescape

\section{2) Attitude for preservation of RFV}

To capture the individual's attitudes, we shall pay attention to their consciousness and willingness to preserve RFV. The attitude may differ according to their types of image formation about rural lifescape. To clarify this point, we shall discuss the next two viewpoints. First, we shall investigate their consciousness to preserve farming villages by asking "Yes" or "No" on two different policies: the preservation policy for a specific farming village and that for all over the country. It is easier to make their decisions for the former policy (local policy) than for the latter (global policy), because the former policy is the one where subjects can have concrete ideas about what's going on in farming villages. Second, we shall pay attention to a set of changes in the subject's attitudes after giving some visual information about rural lifescape.

On the process of a PC automated questionnaire, subjects make paired comparisons of photos related to rural lifescape, which are structured according to an AHP (Analytic Hierarchical Process) algorithm. (the set of photos consists of three groups, each of which have five photos corresponding to three kinds of the images as above. As paired comparisons are made in each group, the required number of comparisons is 30 . The contents of photos are shown in Table 1).

What can we expect in this experiment in relation to the change in their attitudes? First of all, we will find the illuminating effect of the testing experience itself. That is to say, each subject's attitudes for preservation of farming villages will become affirmative after making paired comparisons of photos, because the photos seem to spark in them a good impression about rural farming villages. But our interest was not in this point. According to the viewpoints stated above, we investigated the consistency of their consciousness towards preserving RFV in two different policies and the differences in directions of change in each subject's attitudes, which might be related to their attributes of physical and social environments and past experiences in RFV during childhood. On these points, we can formulate the next two hypotheses.

H2: After the subject has viewed paired comparisons of photos, the consciousness regarding preservation of rural farming villages for all over the country changes more than that of preservation of specific farming village.

H3: The magnitude of the change in the attitudes regarding preservation of rural farming villages after the subject has viewed paired comparisons of photos has a significant relation to the subject's past experiences in RFV and their image of life.

The second hypothesis can be stated based on the assumption that after viewing paired comparisons, the subjects would revise their expressions of the consciousness of policies which preserve farming villages all over the country, and would give them more compatibility with the preservation policy for a specific farming village. ${ }^{6)}$ We think this phenomenon could be considered as a learning process. The third hypothesis means that the attitudes of subjects who have substantial past experiences and an image of life are more vulnerable and changeable. As a note of clarification, the magnitude of the change does not necessarily mean an aggregation of positive changes of the subject's attitudes. We add here that there is a possibility of negative changes in the attitudes of the subjects (from an affirmative attitude to a negative one). 
Table 1. Explanation of photos given in the AHP survey to form respondents' images of RFV

\begin{tabular}{l|l}
\hline \multicolumn{1}{c|}{ Type of image } & \multicolumn{1}{c}{ Corresponding photos, of which paired comparisons were made } \\
\hline Nature & $\begin{array}{l}\text { a rice field just after planting, a rice field just before reaping, an insect stopping on } \\
\text { a flower, buds at a footpath between rice fields, a farming village from the sky }\end{array}$ \\
\hline Life & $\begin{array}{l}\text { an operation by a cultivator, the operation of rice drying, a bamboo hat being made } \\
\text { by an old woman, children playing in a rice field, farmers with smiling faces }\end{array}$ \\
\hline Culture and history & $\begin{array}{l}\text { a Shinto shrine torii surrounded by greenery, a children's festival, old stone monu- } \\
\text { ments, a farming house with thatched roofs, a sacred event at a shrine }\end{array}$ \\
\hline
\end{tabular}

\section{Carrying out the Survey and Measuring the Value of a Rural Farming Village}

\section{1) The flow of the survey}

The set of data we will use in the paper is one which our research group had surveyed to measure a value of the landscape of a rural farming village that had received a grand prize by Ministry of Agriculture, Forestry, and Fisheries (MAFF) for the best landscape panorama. The survey had been carried out over two years (1998-1999) by using a PC automated questionnaire system, which was composed of two parts. One of the parts was a CVM questionnaire to measure a value of the landscape where each subject made a dichotomous choice (DC-CVM) on whether or not he would pay a given sum of money to protect the landscape of the farming village (this was oriented to a purchasing behavior in a micro-economics framework). The other part was an AHP questionnaire to figure out the subjects' image of the farming villages.

Figure 2 shows the overall flow of the survey. In 1999, MAFF implemented a preservation policy of direct payments to hilly and mountainous areas. This carried an implication to save farmhouses which were located in remote villages disadvantaged in productivity. Iide town is such a typical Japanese village where rice fields are spread out all over the town. In 1994, Iide town won the highest award (the award of MAFF) in the first contest for beautiful landscape villages in Japan.

In the paper questionnaire, subjects' attributes related to rural farming village (see Fig. 2, (1)(2)(3), the strength of subject's images of nature, life and tradition on farming villages (4), and "Yes" or "No" on the policy of direct payments to hilly and mountainous areas (5) were surveyed. Questions (5) and (6), and (11) and(9) which were their respective equivalent questions on the repeat test cycle, correspond to the consciousness regarding the farm village preservation policy for all the country and a specific farming village respectively. Questions (7) (10) and (8) are for CVM, and AHP respectively. Because subjects were young persons who at the time of the survey didn't live in rural farming villages, some opinions of both policies are shown for reference, and a choice of preservation is also accepted in (5)(11)). Only subjects who answered "Yes" in (6)(9) were required to answer (7) (10). Here, we would like to bring up one question. In DC-CVM, willingness to pay a given sum of money is usually asked using a hypothetical foundation which would receive contributions and carry out a specified objective (7)(10). It seems strange in the theoretical viewpoint of Hicksian measures, because we are expected to design CVM to represent a person's decision to buy private goods and be able to get the goods after making a "Yes" decision. In the usual DC-CVM case, it is not guaranteed for any citizen that the landscape of Iide town would be protected by their payment, for the preservation decisively depends on the other citizens' decision to contribute as well (this refers to the problem on public goods supply or Social Dilemma in game theory). ${ }^{7} \quad$ So our group set two types of questions :

(Type 1) Paying money as a contribution (the usual DC-CVM question method)

(Type 2) Paying money as a deficiency in putting the preservation into practice

In spite of the impracticality of Type 2, in order to find a difference on effectiveness between the two types, we asked for the willingness to pay as if the preservation fund had 


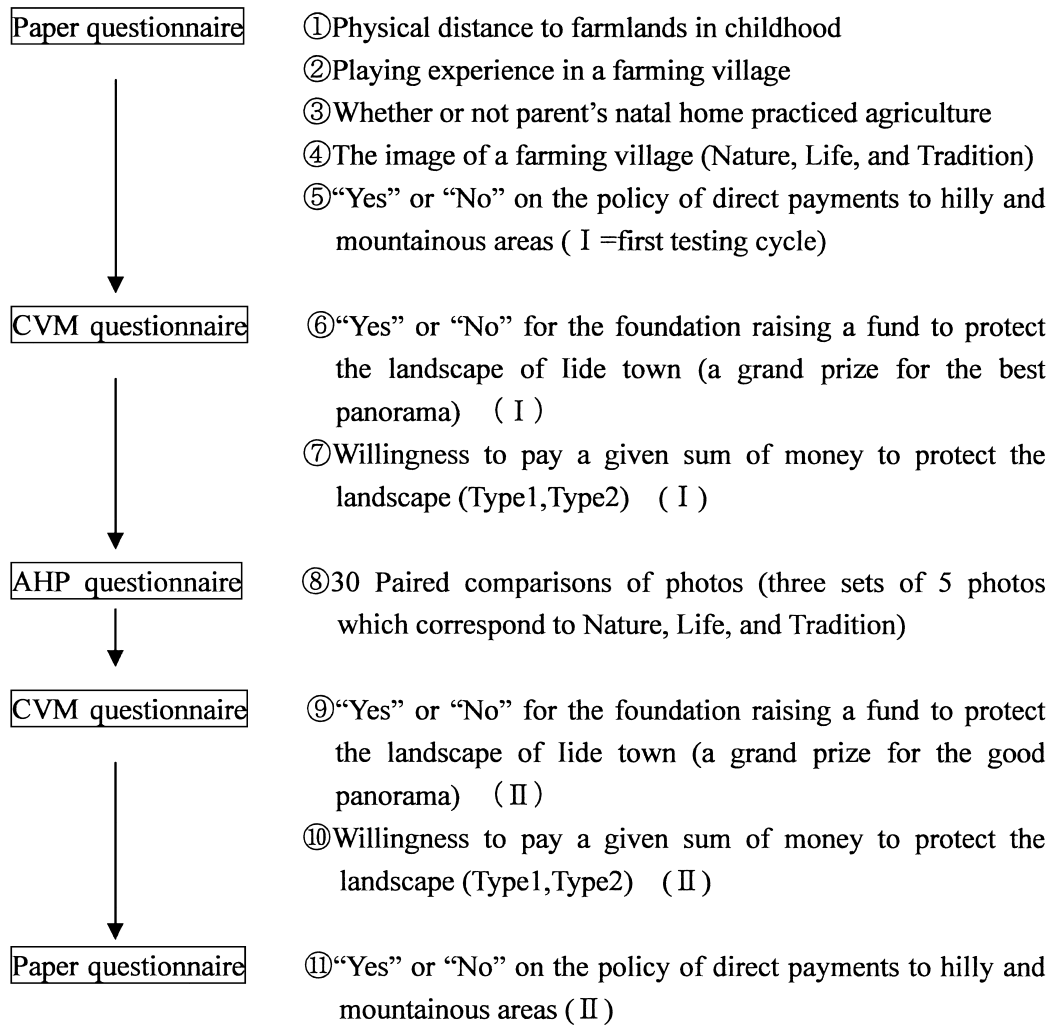

Figure 2. The flow of the survey

already been raised up to the necessary sum of money if the subject decided in the affirmative. ${ }^{8)}$ Accordingly, we formulated the following hypothesis :

H4: Willingness to pay in Type 1 would be smaller than that in Type 2 because of its ineffectiveness to put the policy into force.

In the event that a subject opposes the aims of the foundation, we shall regard that he refused to pay to it (Protest bids). In practice, the subjects of Type 2 were asked about their willingness to pay whether or not they opposed the aims of the foundation. We refer to type 1, type 2 as T1, T2 hereafter.

The exercise was carried out in PC equipped lecture rooms of universities, where we selected subjects who were mainly freshman or sophomore undergraduates students. Because it was necessary for us on the computer to show each subject a different sum of money (DC-CVM), a different type (T1, T2), and to give him/her photos for paired comparisons in random order(AHP), we could not get many survey forms completed at a time com- pared to the usual method of easily distributing assembled surveys to a large class of students. As stated, the grounds for selecting such subjects was that they would not have a vital interest in RFV and would become a pivotal generation for determining the future policy of preserving RFV. Fortunately, they could easily operate personal computers. To consider the difference in the nature of the subjects' environments in childhood, we also carried out the exercise in Hokkaido and Okinawa, each of which is located at the northern and southern ends of Japanese islands respectively. These areas have largely different types of agriculture from Honshu (the central main island in Japan). The number of samples was 631 (269 in Honshu, 137 in Hokkaido, and 225 in Okinawa). ${ }^{9}$

2) Measurement of willingness to pay for protecting a specific rural farming village

Figure 3 shows ratios of willingness to pay according to type and pre and post-AHP. Willingness to pay on $\mathrm{T} 2$ seems higher than 


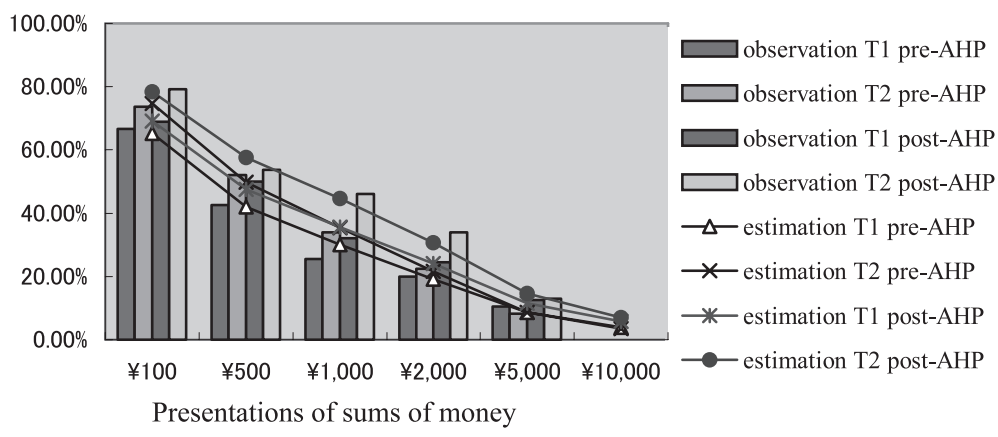

Figure 3. Ratio of willingness to pay according to type and pre- and post-AHP

that on T1. In fact, we calculated the median WTP using logistic regression estimation curves shown in Fig. 3, and we got $¥ 305$. 58, $¥ 427.92$ on $\mathrm{T} 1$ and $¥ 491.54, \quad ¥ 762.25$ on T2, where the former value was at pre-AHP and the latter was at post-AHP, respectively. In almost all of the 10 combinations (2 times and 5 presentations of sum of money) except under the conditions of pre-AHP presented at $¥ 5,000$, willingness to pay on T2 was higher than that on T1. Therefore, we can say there was a difference between the two types statistically (nonparametric test at a $5 \%$ significance level). As a result, we posit a fourth hypothesis :

There would be a possibility that many calculated values of CVM based on contributions to a hypothetical foundation have been underestimated.

\section{Factors of Consciousness and Willingness to Protect PFV}

\section{1) Verification of the model for image formation}

The result of path analysis to verify the model for image formation is shown in Fig. 4 (residual terms are omitted). Significant causal relationships are shown by bold lines with correlation coefficients. According to this diagram, the amount of past experiences of having played during childhood in a RFV are strongly determined by physical distance to farmlands and whether the parent's home practiced agriculture or not, and this in turn leads to the formation of the image of life. These results support the first hypothesis H1. Practice of agriculture at the parent's natal home gave a direct negative effect on the student's image of culture and history. This means that students who were not familiar with agriculture tended to form a strong image of culture and history. Furthermore, the image of nature was not correlated with attributes of physical and social environments and past experiences in a RFV in childhood (in fact, the correlation coefficient between the image of nature and the amount of past experiences of having played in RFV as a child is negative although it is not significant). As a result, the image of life is different from the other two images, and this image is only related to attributes of physical/ social environments and past experiences in RFV during childhood.

2) The image of rural lifescape and attitudes to preserve rural farming villages

Table 2 shows the result of a regression analysis where dependent variables were selected from the image formations models in Figure 1 and independent variables are attitudes to preserve rural farming villages. To be specific, this meant answering "Yes" or "No" regarding the foundation raising a fund for protecting the landscape of Iide town, "Yes" or "No" on the policy of direct payments to hilly and mountainous areas, and willingness to pay a given sum of money to protect the landscape. According to the results, consciousness to support the foundation was positively explained by the total image of rural lifescape, especially on nature and culture/history. On the other hand, consciousness to support the policy of direct payments is positively explained by images of life and culture/history, and negatively by the image of nature. Willingness to pay is also explained by the total image of rural lifescape, and it is very interesting that a 


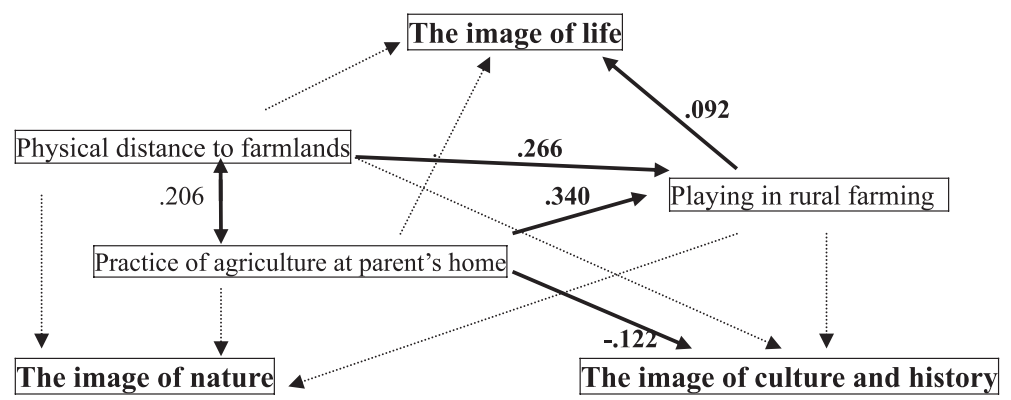

Figure 4. Image formation of rural lifescape

Table 2. Attitudes to protect rural farming villages according to the image of rural lifescape

\begin{tabular}{|c|c|c|c|c|c|c|}
\hline \multirow[t]{2}{*}{ Independent variables } & \multicolumn{2}{|c|}{$\begin{array}{l}\text { Yes/No on the } \\
\text { foundation }\end{array}$} & \multicolumn{2}{|c|}{$\begin{array}{l}\text { Yes/No on the } \\
\text { policy of direct } \\
\text { payments }\end{array}$} & \multicolumn{2}{|c|}{ Willingness to pay } \\
\hline & Pre-AHP & Post-AHP & Pre-AHP & Post-AHP & Pre-AHP & Post-AHP \\
\hline Physical dist. to farmland & & & & $-.082^{*}$ & & \\
\hline Practice of agriculture & & & & & & \\
\hline Play in RFV & & & +.073 & & & $+.111^{* *}$ \\
\hline Image of nature & $+.076^{*}$ & $+.081^{*}$ & $-.086^{*}$ & & $+.079 *$ & +.077 \\
\hline Image of life & +.064 & $+.075^{*}$ & & $+.114^{* *}$ & +.072 & $+.080^{*}$ \\
\hline Image of culture/history & $+.112^{* *}$ & $+.086^{*}$ & $+.117^{* *}$ & & & $+.078^{*}$ \\
\hline Disposable income & - & - & - & - & $+.088^{*}$ & $+.076^{*}$ \\
\hline $\boldsymbol{R}^{2}$ & $.036^{* *}$ & $.033^{* *}$ & $.027^{*}$ & $.024^{*}$ & $.031^{*}$ & $.043^{* *}$ \\
\hline
\end{tabular}

Partial regression coefficients (displayed only when $p<0.2$ ).

${ }^{*} p<0.1,{ }^{* *} p<0.05$.

positive and significant correlation between willingness to pay and playing experience in rural farming villages appeared after the AHP exercise.

To sum up, consciousness on preserving $\mathrm{RFV}$ is largely influenced by the image of rural lifescape, and the image of nature has a positive relation only with respect to the consciousness of protecting a specific rural landscape. Images of life and culture and history have a relation to the general nation-wide preservation of rural farming villages. Pastexperience in rural farming villages and the image of life both enhanced the strength of the relationship to consciousness and willingness to preserve the RFV after the AHP exercise.

It would be possible to interpret the above to mean that only students who had experienced rural farming villages in the past and formed their image of life could feel a paraexperience in rural villages during the AHP exercise. We shall discuss this point later.

\section{Changes in Attitudes on Preserving RFV}

1) Changes in consciousness and willingness to pay after the AHP exercise

The ratio of approval for the foundation of protecting landscape increases slightly after the AHP exercise ( $81.1 \%$ to $82.4 \%$ ), but we can see that the result was not significant statistically. Moreover, the ratio of subjects who changed their decisions after the AHP exercise (from approval to opposition or from opposition to approval) was $6.0 \%$. Therefore, we could say that the decision was robust through paired comparisons of photos. On the contrary, the ratio of approval for the policy of direct payments increased largely after the AHP exercise (77.0\% to $82.8 \%$ of the group excluding those who answered "can't tell" in both the pre- and post-AHP exercise). The ratio of "can't tell" decreased to $11.9 \%$ from $19.5 \%$ and more than half $(55 \%)$ 
Table 3. Change in the relationship of Yes/No between the two policies of creating a foundation for protecting the landscape and direct payments to disadvantaged farming villages

〈Pre-AHP exercise〉

\begin{tabular}{ccccccc}
\hline Direct payments & Approval & $\begin{array}{c}\text { Approval } \\
\text { a little }\end{array}$ & $\begin{array}{c}\text { Opposition } \\
\text { a little }\end{array}$ & Opposition & Can't tell & Total \\
\hline Protecting landscape & 104 & 235 & 58 & 9 & 100 & 506 \\
Approval & $86.7 \%$ & $88.3 \%$ & $60.4 \%$ & $50.0 \%$ & $83.3 \%$ & $81.6 \%$ \\
Opposition & 16 & 31 & 38 & 9 & 20 & 114 \\
Total & $13.3 \%$ & $11.7 \%$ & $39.6 \%$ & $50.0 \%$ & $16.7 \%$ & $18.4 \%$ \\
\hline
\end{tabular}

Gamma coefficient $\mathrm{G}=-0.461$.

〈Post-AHP exercise〉

\begin{tabular}{ccccccc}
\hline Direct payments & Approval & $\begin{array}{c}\text { Approval } \\
\text { a little }\end{array}$ & $\begin{array}{c}\text { Opposition } \\
\text { a little }\end{array}$ & Opposition & Can't tell & Total \\
Protecting landscape & 141 & 290 & 23 & 3 & 59 & 516 \\
Approval & $95.9 \%$ & $93.9 \%$ & $31.9 \%$ & $13.0 \%$ & $77.6 \%$ & $82.3 \%$ \\
Opposition & 6 & 19 & 49 & 20 & 17 & 111 \\
Total & $4.1 \%$ & $6.1 \%$ & $68.1 \%$ & $87.0 \%$ & $22.4 \%$ & $17.7 \%$ \\
\hline
\end{tabular}

Gamma coefficient $\mathrm{G}=-0.857$.

$G=-0.831$ : excluding subjects who "can't tell” at pre-AHP.

of the subjects who responded "can't tell" in their pre-AHP exercise, expressed their approval (83.3\%) during the post-AHP. As a result, the ratio of approval during the postAHP was $82.9 \%$ (refer to Table 5).

On the other hand, the ratio of subjects who changed their decisions on the policy of direct payments after the AHP exercise (from approval to opposition or from opposition to approval) was $14.5 \%$ excluding the "can't tell"subjects. Although this ratio was quite larger than that of protecting the landscape, this fact would not contribute to raising the ratio of approval. In fact, there were a considerable number of subjects who changed their decisions from approval to opposition (one-third of the subjects changing their decisions negatively (23 cases)). Uniformly increasing the ratio of approval could be considered to be a kind of illuminating effect that the retest had on the subjects, but what on earth could account for the change of decision on both sides?

As shown in Table 3, the correlation between the attitude for protecting landscape and that for direct payments is significant and high. To pay close attention to the coefficients, the correlation after AHP was much higher than before AHP (from 0.471 to 0.857 in terms of $\gamma$-coefficients). This means that the attitude for protecting landscape changed to be consistent with that for direct payments, which was robust through the AHP exercise. In other words, the consciousness for protecting a specific rural farming village extends to that of preserving hilly and mountainous villages nation-wide, ${ }^{10}$ ) which we posit in the second hypothesis $H 2$.

The ratio of subjects who are willing to pay also significantly increased from $36.2 \%$ to $42.8 \%$. The number of protests (that is, the number of subjects who opposed creating the foundation) was almost the same between pre- and post-AHP, and more than $80 \%$ of protests remained opposed. This fact indicates that the increase of willingness to pay was simply caused by subjects who changed their willingness to pay from not paying.

When we researchers intend to make subjects heighten their consciousness to preserve RFV or guide them to approve such policies, it is possible to consider the above-stated 
facts as illuminating or a commitment on their actions. Although we cannot avoid these situations in carrying out this kind of survey, our aims to study here was not on these points, but rather to understand some decision-making structures for preserving RFV and conduct an exercise on the relationship of them to the subjects' attributes.

2) Changes of decision in relation to the image and past experiences in rural villages

We expected a difference in decision-making between the groups which would be classified by the image and past experience on RFV (which would give each subject a different meaning of farming villages). To investigate the influence of paired comparisons of photos on an attitude of a specific group for preserving RFV, it is insufficient to see only the aggregated changes in the group. First, there were a considerable number of subjects who couldn't express their attitudes, especially those regarding the policy of direct payments, and many of them expressed their attitudes after the AHP exercise. Second, as stated above, we can't see any aspect of the change without seeing it on both sides (preand post-AHP) through individuals. We shall give some indicators based on these points.

In order to consider the influence of subjects who were indecisive about the policy of direct payments or resisted creation of the foundation for protecting landscape, we computed the ratio of approval after the AHP exercise excluding subjects who couldn't tell or resisted during the pre-AHP. We shall list four indicators as follows ;

$\delta$ : a ratio of subjects who change their decision from opposition (not willing to pay) to approval (willing to pay) or its reverse, excluding subjects who can't tell or resist.

$r$ : a gamma coefficient between decisions of pre- and post-AHP, in view of consistency of their decisions.

$\rho$ : a ratio of subjects who changed their decision to approval (willing to pay) from those who opposed (are not willing to pay) during pre-AHP.

$\zeta$ : a ratio of subjects who changed their decision to opposition (not willing to pay) from those who approved (is willing to pay) during pre-AHP.
Both $\delta$ and $r$ indicate the amount of change, but we want to bring attention to the fact that the smaller value of $r$ that appears, the larger the amount.

In Tables 4 and 5 , changes of willingness to pay and consciousness are shown according to each attribute related to RFV (Natural/Social environments, past experiences in childhood, and the image of RFV). The symbol* means a significant difference occurred between categories by the statistical test of difference (significant level is 10\%). The amount of change in the ratio of willingness to pay was closely related to three variables: distance from farming fields in childhood, past experience of playing in farming fields during childhood, and the image of life. Moreover, we found that a past experience of playing and having an image of life predisposed subjects to change 'not willing' to 'willing. ' In the retest curious results in the degree of increased responses of practicing agriculture at the parents' natal home, the image of nature, and the image of culture and history seems to be caused by a recovery process from the accidental responses that occurred during the pre-AHP.

The amount of change in the ratio of approval for the policy of direct payments to hilly farming villages is closely related to four variables : distance from farming fields in childhood, past experience of playing in farming fields in childhood, the image of life, and the image of culture and history. In the group of having been near farming fields in childhood, we found a considerable amount of subjects who changed their decision from approval to opposition, which made the ratio of approval lower than any other categories. We also confirmed a similar tendency in the group having past experiences playing in farming fields during childhood, the image of life, and the image of culture and history. Therefore, the "vulnerability of the decision" can be considered as a property that RFV-familiar subjects have (H3).

\section{3) Discussion}

Here, we shall discuss three points: what we can say about the change of attitudes for preserving rural farming villages in relation to the model of image formation, how to interpret a change in the decision, especially a negative change, and how to deal with illumi- 
Effects of Image Formation of Rural Lifescape on Consciousness and

Willingness to Protect Rural Farming Villages

Table 4. Willingness to pay for the foundation protecting landscape of Iide town

\begin{tabular}{|c|c|c|c|c|c|c|c|c|}
\hline \multirow{2}{*}{$\begin{array}{l}\text { Attributes } \\
\text { in relation } \\
\text { to farming }\end{array}$} & \multicolumn{4}{|c|}{ Ratio of willingness to pay } & \multicolumn{4}{|c|}{ Ratio of change of decision } \\
\hline & Pre-AHP & (a) ${ }^{\mathrm{P}}$ & P (b) & $\begin{array}{l}\text { Amount of } \\
\text { increase } \\
\text { (b) - Pre-AHP }\end{array}$ & $\rho$ & $\zeta$ & $\delta$ & $r$ \\
\hline Total & 36.2 & 42.8 & 42.1 & $5.9^{*}$ & .110 & .032 & .067 & 991 \\
\hline \multicolumn{9}{|c|}{ Distance from farming fields in childhood } \\
\hline Near & 35.8 & 43.9 & 43.6 & 7. $8^{*}$ & .115 & .000 & .057 & 1.000 \\
\hline Apart from & 32.4 & 39.5 & 38.8 & 6.4 & .109 & .045 & .075 & .987 \\
\hline None & 38.7 & 42.6 & 41.9 & 3.2 & .084 & .040 & .055 & 992 \\
\hline \multicolumn{9}{|c|}{ Practicing agriculture at parents' home } \\
\hline Both & 38.0 & 40.8 & 40.0 & 2.0 & .097 & .053 & .083 & .987 \\
\hline One of them & 32.7 & 44.4 & 44.3 & 11. $6^{*}$ & .152 & .000 & .082 & 1. 000 \\
\hline None & 37.9 & 42.9 & 42.1 & 4.4 & .099 & .048 & .065 & .988 \\
\hline \multicolumn{9}{|c|}{ Past experience of playing in farming fields in childhood } \\
\hline Every day & 39.8 & 51.2 & 50.0 & 10.2 & .200 & .030 & .104 & 984 \\
\hline Sometimes & 37.5 & 44.0 & 44.4 & $6.9^{*}$ & 108 & .038 & .069 & 990 \\
\hline None & 33.3 & 38.3 & 37.0 & 3.7 & .083 & .028 & .052 & 994 \\
\hline \multicolumn{9}{|c|}{$\begin{array}{l}\text { The image on RFV } \\
\text { The image on natural scenery }\end{array}$} \\
\hline Essential & 40.4 & 45. 2 & 44.8 & 4. 4 & 089 & .036 & .056 & .992 \\
\hline A little & 25.9 & 37.1 & 36.7 & $10.8^{*}$ & 147 & 000 & .069 & 1. 000 \\
\hline Unrelated & 42.9 & 45.0 & 39.1 & -3.8 & .083 & .111 & .056 & .975 \\
\hline \multicolumn{9}{|c|}{ The image on life scenery } \\
\hline Essential & 41.0 & 49. 4 & 48.7 & 7. $7^{*}$ & .150 & .033 & .086 & .987 \\
\hline A little & 29.4 & 35.2 & 34.3 & 4.9 & .078 & .021 & .050 & .996 \\
\hline Unrelated & 30.0 & 28.3 & 30.0 & 0.0 & .000 & .067 & .014 & 1.000 \\
\hline \multicolumn{9}{|c|}{ The image of culture and history } \\
\hline Essential & 45.1 & 51.1 & 50.7 & 5.6 & .115 & .047 & .056 & .986 \\
\hline A little & 34.2 & 41.9 & 41.8 & 7. $6^{*}$ & .113 & .014 & .068 & .996 \\
\hline Unrelated & 31.9 & 36.9 & 35.5 & 3.6 & .098 & .039 & .059 & 990 \\
\hline \multicolumn{9}{|c|}{ Disposable income (pocket money) } \\
\hline 一 $¥ 20,000$ & 34.7 & 41.1 & 40.8 & 6.1 & .087 & .015 & .052 & 997 \\
\hline - $¥ 40,000$ & 33.2 & 39.7 & 39.1 & 5.9 & .126 & .063 & .085 & 980 \\
\hline$¥ 40,001-$ & 44.5 & 49.6 & 48.3 & 3.8 & 091 & 019 & .046 & 998 \\
\hline
\end{tabular}

Post-AHP(a) : excluding all subjects who resisted against the foundation at pre- or post-AHP.

Post-AHP(b) : excluding only subjects who resisted against the foundation at post-AHP.

nating effects or impingement on subjects' decisions by the PC questionnaire system.

First, under the model of image formation, we assume that an image of life would be deepened by having a para-experience through viewing paired comparisons of many photos on RFV. To contrast with an image of nature and to some degree the category of "culture and history" which are influenced largely by physical environments, an image of life is formed mainly through social relationships or kinship manifested by the subject's own so- 
Table 5. Consciousness for the policy of direct payments to hilly farming villages

\begin{tabular}{|c|c|c|c|c|c|c|c|c|}
\hline \multirow{2}{*}{$\begin{array}{l}\text { Attributes } \\
\text { in relation } \\
\text { to farming }\end{array}$} & \multicolumn{4}{|c|}{ Ratio of approval } & \multicolumn{4}{|c|}{ Ratio of change of decision } \\
\hline & Pre-AHP & (a) ${ }^{\mathrm{P}}$ & (b) & $\begin{array}{l}\text { Amount of } \\
\text { increase } \\
\text { (b) -Pre-AHP }\end{array}$ & $\rho$ & $\zeta$ & $\delta$ & $r$ \\
\hline Total & 77.0 & 82.8 & 82.9 & $5.9^{*}$ & .404 & .061 & .112 & .902 \\
\hline \multicolumn{9}{|c|}{ Distance from farming fields in childhood } \\
\hline Near & 79.8 & 81.7 & 80.6 & 0.8 & .400 & .094 & .130 & .836 \\
\hline Apart from & 72.2 & 81.0 & 81.1 & 8. $9^{*}$ & .429 & .055 & .127 & .904 \\
\hline None & 77.8 & 85.2 & 85.9 & 8. $1^{*}$ & .425 & .036 & .095 & .941 \\
\hline \multicolumn{9}{|c|}{ Practicing agriculture at parents' home } \\
\hline Both & 81.8 & 88.1 & 84.6 & 2.8 & .375 & .000 & .053 & 1. 000 \\
\hline One of them & 76.7 & 82.8 & 83.1 & $6.4^{*}$ & .432 & .074 & .130 & .856 \\
\hline None & 77.9 & 83.8 & 84.2 & $6.3^{*}$ & .441 & .063 & .117 & .886 \\
\hline \multicolumn{9}{|c|}{ Past experience of playing in farming fields in childhood } \\
\hline Every day & 78.2 & 84.7 & 80.9 & 2.7 & .526 & .088 & .154 & $.757^{*}$ \\
\hline Sometimes & 77.3 & 83.6 & 84.0 & $6.7^{*}$ & .457 & .053 & .123 & $.891^{*}$ \\
\hline None & 77.0 & 82.1 & 83.3 & $6.3^{*}$ & 319 & .051 & .087 & $.941^{*}$ \\
\hline \multicolumn{9}{|c|}{$\begin{array}{l}\text { The image on RFV } \\
\text { The image on natural scenery }\end{array}$} \\
\hline Essential & 76.5 & 81.6 & 81.8 & $5.3^{*}$ & .390 & .060 & .110 & .912 \\
\hline A little & 78.3 & 86.0 & 86.0 & 7. $7^{*}$ & .387 & .045 & .097 & .922 \\
\hline Unrelated & 82.8 & 82.1 & 80.6 & -2.2 & .600 & .125 & .167 & .633 \\
\hline \multicolumn{9}{|c|}{ The image on life scenery } \\
\hline Essential & 77.9 & 85.6 & 84.8 & $6.9^{*}$ & .517 & .047 & .119 & $.893^{*}$ \\
\hline A little & 82.1 & 84.6 & 84.9 & 2.8 & .400 & .080 & .114 & $.860^{*}$ \\
\hline Unrelated & 62.7 & 66.0 & 68.4 & 5.7 & .091 & .054 & .056 & $.985^{*}$ \\
\hline \multicolumn{9}{|c|}{ The image of culture and history } \\
\hline Essential & 82.2 & 86.4 & 84.4 & 2.2 & .478 & .047 & .097 & .910 \\
\hline A little & 81.8 & 84.2 & 85.1 & 3.3 & .382 & .065 & .098 & .907 \\
\hline Unrelated & 69.4 & 79.1 & 79.7 & 10. $3^{*}$ & .375 & .063 & .132 & .901 \\
\hline
\end{tabular}

Post-AHP(a) : excluding all subjects who can't tell about the policy at pre-or post-AHP.

Post-AHP(b) : excluding only subjects who can't tell about the policy at post-AHP.

cial experiences in rural villages or parents' own experiences in their natal farming villages. So we suppose that the image is not the one of a specific rural village such as Iide, but rather one that corresponds to an affinity with rural villages nation-wide. Thus, we could accept the increase of approval on the policy of direct payments which was largely brought by the change of decisions from opposition to approval.

Secondly, in the group having lived near the farming fields during childhood, some subjects changed their decisions from positive to negative as stated above. Moreover, there was the same phenomenon in the group having past experiences of playing in RFV. These groups also have many subjects who changed from negative to positive decisions. That is, the decision of subjects in these groups seems to be vulnerable and inconsistent throughout the AHP exercise.

Thirdly, although visual and narrative in- 
formation by the PC questionnaire system clearly gives strong effects on the attitude for preserving RFV, there were some effects that we can not regard entirely as illuminating or impinging on the subjects' decisions by the PC system. An illuminating effect, we think, is one which gives all subjects the same influence (e.g. the same direction of change of their decisions), and impingement means that our system restricts all subjects' decisions in the same manner. Indeed, our PC questionnaire system had such an illuminating effect (impingement on subjects' decisions) as a whole, but it would be appropriate for us that the change of subjects' attitudes be considered from some different viewpoints, especially consciousness regarding the policy of direct payments, because we have already seen a conformity of the two attitudes (approval/opposition for/against protecting a specific farming village and farming villages all over the country), and because we can't see the change of decisions in the same direction.

In the end of this section, we shall try to explain the change in two contexts : learning process (acquiring consistency) and capability (an ethical point of view). The first point of view on the alternation of subjects' decisions is a learning process, where they would try to conform their decisions on the two types of policies : protecting a specific landscape of a rural farming village and on the preservation of nation-wide. Of course, the decisions might not be made using the same standard, but it would be reasonable for us to understand that these two policies would become common to many subjects after the AHP-exercise.

The second point is more difficult to understand. Thus, we shall propose a brief framework that make sense of the subjects' behaviors before and after the AHP exercise. In theories on modern distributive justice, we can see some excellent conceptions about what should be distributed to citizens in order to avoid the welfarism which had involved the notorious conception, utilitarianism. Some examples are equalisandum, social primary goods by Rawls [16], capability by Sen [19], and resources by Dworkin [4]. Here, we shall focus on capability. Sen [19] says that various economical goods to be dis- tributed should be captured in their "functionings," and societies should equalize the set of functionings (which is called capability) on each citizen. A set of functionings doesn't necessarily mean a utility which is assumed to be brought about by consuming economical goods. The essential thing is what the goods give a citizen comprehensively. So, some say that in some cases capability means the number of choices that citizens would make. But we think the choices should not be counted as capability if things that would be brought by them have little meaning. Thus, we want to state that being different from economic goods, the evaluation on things brought by the choices are not always positive for citizens. ${ }^{11)}$

To apply this discussion to our survey, subjects who had no connection to RFV and who opposed preserving RFV changed their minds and regarded them as favorable goods after the AHP exercise. On the other hand, subjects who had been familiar with RFV had PC para-experiences and changed their minds according to their past experiences. Changes would occur on both sides (approval to disapproval/disapproval to approval) and the amount of them here would be larger than that of RFV subjects who had no prior connection with rural villages. In conclusion, RFV-familiar citizens might have greater capability than RFV-non connected ones in the sense that the former had more various contextual effects than the latter.

\section{Conclusion}

We have proved four hypotheses stated in sections 2 and 3 using statistical methods. (1) An image of life was largely formed by past experiences in RFV and natural/social access to RFV in childhood. (2) AHP exercises gave a conformity of the subjects' attitudes on protecting local and preserving nationwide RFV. (3) Subjects who had much past experience in RFV and had formed an image of life on them tended to change their decisions on preserving RFV considerably after the AHP exercise, but the decisions were not necessarily positive. (4) Willingness to pay in DC-CVM by the usual questioning method (whether or not the respondent will contribute to the foundation for remediating environments) resulted in a smaller value than 
the theoretical compensating surplus.

We shall focus on the third statement and interpret it in the framework of capability. Recently, many researchers of agricultural economics have emphasized multi-dimensional functionings of RFV and they have been measuring the values based on using micro economic models. However, the values that were not directly based on physical properties of RFV ; such as social aspects, lives, and existence of RFV itself ; are easily enhanced in citizens who had no prior connection to RFV, because we can present information about RFV as a favorable economic good. The thing that we would like to say is that we should recognize another kind of value of the RFV, namely, the ethical "capability" viewpoint and framework proposed herein.

1) Heller [7] says "An important element of the demand for preservation may derive less from its instrumental utility than from its symbolic meaning." We suppose symbols have semiotic values that serve human well-being, besides emblematic ones of charismatic species that would serve general nature conservation to which Kontoleon and Swanson [11] refers.

2) We regard the symbolic value as a kind of intrinsic values, to which Primack [15] has referred as justifying the preservation of biodiversity (p.239). As Turner [23] has noted, some symbols may take on multiple meanings such as the milk tree for the New Guinea Ndembu while others may condense meaning. In view of environmental ethics, Callicott [3] says "Everything equally has an intrinsic or inherent value in view of biocentrism." As a warning to the farm economics of industrialization, Ikerd [8] says "But perhaps more important, relationships between farmers and their customers can be one of the most important aspects of finding a more desirable interpersonal quality of life through farming."

3) For example, see O’Doherty [14].

4) Regarding the issue of rural farming from ethical points of view, Thompson [22] took up the topic of the value of family farming, Mepham [12] asked how we could manage the influence of agribusiness on rural agriculture. Still further, Shrader-Frechette [18] called for the government to protect family farms. We consider that the values on "rural" or "family" might be embedded in lifescape visions. The term lifescape was first coined by Bellows et al. [1].

5) For the value of a Japanese historical village,
Fujimoto [5] measured and compared the results of various market models including. For comparisons with the values of environmental assets assuming market mechanisms, refer to Bishop, et al. [2] for example.

6) Kahneman and Knetsch [9] pointed out that CVM results are prone to have an embedding effect. We don't intend to give any new insights to the effect here, but rather to spark an awareness of the non-use value of farming villages in some respondents. Just for reference, a specific farming village might be a potential means for greater preservation of farming villages as Kontoleon and Swanson [11] noted that the symbolic nature of the panda might be for greater biodiversity conservation.

7) Sen [21] pointed out that the independence of choice in CVM for measuring environmental public goods wouldn't be satisfied, because people might expect the other people's contribution to the goods, which would not happen in case of measuring private goods. We think researchers of environmental economics have adopted realizable and practical questionnaires in CVM scenarios, but not ones truly faithful to Hicksian theory yet, because it is natural for a policy-maker to suppose a hypothetical fund and contributions to the fund when asking subjects' willingness to pay for protecting the landscape, and because they often have been required to aggregate representative sums of money to show the total value of the landscape.

8) To ask respondents' willingness to pay, the inquiry statement figured in the survey is :

Type 1. Can you afford to pay** yen per month from your income to help support this fund?

Type 2. Assume that ${ }^{* *}$ yen per month will cover the insufficiencies of the fund and be able to keep the town's beautiful scenery. Can you keep covering the money expenses?

9) Prompt reports on the survey are referred to Nomura et al. [13] and Kitani et al. [10]. The former shows the figures for the PC automated questionnaire system for CVM and AHP, and the latter shows some key-results of the survey.

10) Hasebe, et al. [6] surveyed the attitudes for protecting RFV in Korea in the same way we did here. In Korea, the increase of this correlation after AHP was very small and respondents approved the policy of direct payments larger than those in Japan. We think that the difference was caused by the abundance of people having RFV experiences, for many Koreans are more familiar with RFV than Japanese and are 
prone to evaluate nation-wide RFV as a use value in the same way that they evaluate a specific RFV.

11) Sen [20] differentiates the agency aspect from the well-being aspect of a person. He says, "Another important issue concerns the very different roles that the well-being and the agency aspects can have in the use of interpersonal comparisons for diverse exercises." ( $p$. 70) We think RFV-familiar subjects can only change their attitudes as an agent after PC para-experiences, some of which often look like negative changes in 'monist' conception of well-being.

\section{References}

[1] Bellows, B. C., G. Buenavista, and M. Ticsay-Rusco, eds., Participatory Landscape/ Lifescape Appraisal, Vol.1. SANREM CRSP Research report 2-95. Sustainable Agricultural and Natural Resource Management CRSP, University of Georgia, 1995

[2] Bishop, R. C., T. A. Heberlein, and M. J. Kealy. "Contingent Valuation of Environmental Assets: Comparisons with a Simulated Market," in K. G. Willis, et al. eds., Environmental Valuation 2., Edward Elgar Publishing Limited, 1999, pp. 97-111.

[3] Callicott, J. B. In Defense of the Land Ethic. Albany, NY : SUNY Press, 1989.

[4] Dworkin, R. "What is Equity? Part 2 : Equality of Resources," Philosophy and Public Affairs, Vol. 10, 1997, pp. 283-345.

[5] Fujimoto, T. "Rekishiteki Keikan-Iji no tameno Nochi Hozen-seisaku no Beneki to Hiyou no Hyoka-Asuka-mura ni okeru Keisu-sutadei (Evaluation of Benefits and Costs of Rural Land-Use Policy for the Conservation of Historical Landscape: A Case Study of Asuka Village)," Noson Keikaku Gakkai-shi (Journal of Rural Planning Association), Vol. 17, 1998, pp. 40-50.

[6] Hasebe, T., S. Kitani, and N. Nomura. “Nosonfuukei no Kachi to Joken-furichiiki eno Chokusetsu-siharai (Evaluation of Rural Landscape and Consciousness of the Direct Payment for Less Favored Area)," Nihon Nogyo-KeizaiGakkai Ronbunshu (Proceedings of Annual Conference of the Agricultural Economics Society of Japan), 2002, pp. 166-169.

[7] Heller, T. C. “The Importance of Nomative Decision-Making : The Limitations of Legal Economics as a Basis for a Liberal JurisprudenceAs Illustrated by the Regulation of Vacation Home Development," Wisconsin Law Review, 1976, p. 405.

[8] Ikerd, J. Systems in Agriculture and Land Management, the HRM of TX Annual Confer- ence, 2001 (http ://www. ssu. missouri. edu/ faculty / jikerd / papers / EconomicsofSustainable Farming. htm).

[9] Kahneman, D. and J. L. Knetsch. “ Valuing Public Goods: The Purchase of Moral Satisfaction," Journal of Environmental Economics and Management, Vol.22, 1992, pp. 57-70.

[10] Kitani, S., T. Hasebe, and N. Nomura. "Noson Imeji Keisei ga Nousoniji ni Taisuru Ishiki to Taido ni Ataeru Eikyo (Effects on Consciousness and Willingness to Defend Rural Scenery through the Process of Rural Image Formation)," Nogyo Keizai Kennkyu Houkoku (Journal of Farm Management Economics), Vol. 32, 2000, pp. 13-22.

[11] Kontoleon, A. and T. Swanson. "The Willingness to Pay for Property Rights for Giant Panda : Can You Charismatic Species be an Instrument for Nature Conservation?" Land Economics, Vol. 79(4), 2003, pp. 483-499.

[12] Mepham, B. "Agricultural Ethics," in R. Chadwick, ed., Encyclopedia of Applied Ethics 1. Academic Press, 1998, pp. 95-110.

[13] Nomura, N., S. Kitani, and T. Hasebe. "PC Nabigeitogata Chousa Sisutemu niyoru Kasousijou Hyoukahou no Kokoromi (A Survey System for Contingent Valuation Method by Using PC Navigation Questionnaire)," Nihon Kenchiku Gakkai Gijutsu Houkokushu (AIJ Journal of Technological Design), No. 12, 2001, pp. 219-222.

[14] O'Doherty, R. "Using Valuation to Enhance Public Participation in Local Planning," Regional Studies, Vol. 30, 1997, pp. 667-678.

[15] Primack, R. B. Essentials of Conservation Biology. Sinauer Associates Inc., 1993.

[16] Rawls, J. Theory of Justice. Massachusettes : Harvard University Press, MA, 1971.

[17] Sagoff, M. The Economy of the Earth. Cambridge : Cambridge University Press, 1988.

[18] Shrader-Frechette, K. S. "Agricultural Ethics," in L. C. Becker. and C. B. Becker, eds., Encyclopedia of Ethics 1. Garland Publishing Inc., 1992, pp. 30-33.

[19] Sen, A. K. Commodities and Capabilities. North Holland, 1984.

[20] Sen, A. K. Inequality Reexamined. NY : Oxford University Press, 1992.

[21] Sen, A. K. "Environmental Evaluation and Social Choice: Contingent Valuation and the Market Analogy," The Japanese Economic Review, Vol. 46, 1995, pp. 23-37.

[22] Thompson, P. B. Agricultural Ethics. IA : Iowa State University Press, 1998.

[23] Turner, V. Forest of Symbols. Ithaca, NY : Cornell University Press, 1967.

(Received October 20, 2004 ; accepted January 23, 2005) 